\title{
A Study on the Relationship of Entrepreneurial Orientation and Business Performance in the SMEs of Kurunegala District in Sri Lanka
}

\author{
Deepal N. Perera1, Debanjan Nag1, P. Venkateswarlu² \\ ${ }^{1}$ ICFAI University, Tripura, Agartala, India \\ ${ }^{2}$ ICFAI University, Dehradun, India \\ Email: deepal@expack.lk, debanjannag@iutripura.edu.in, venkat@ibsindia.org
}

How to cite this paper: Perera, D.N., Nag, D. and Venkateswarlu, P. (2019) A Study on the Relationship of Entrepreneurial Orientation and Business Performance in the SMEs of Kurunegala District in Sri Lanka. Theoretical Economics Letters, 9, 2324-2336.

https://doi.org/10.4236/tel.2019.97147

Received: July 29, 2019

Accepted: September 23, 2019

Published: September 26, 2019

Copyright $\odot 2019$ by author(s) and Scientific Research Publishing Inc. This work is licensed under the Creative Commons Attribution International License (CC BY 4.0).

http://creativecommons.org/licenses/by/4.0/

\begin{abstract}
This study was conceived as an attempt to study the relationship of Entrepreneurial Orientation and Business Performance in the Small and Medium Enterprises (SMEs) of Kurunegala District in Sri Lanka. The study was conducted on 275 SMEs in Kurunegala engaged in varied businesses including coconut products, rubber based products, garments and apparels, cement and clay pots, housing and real estate etc. The Entrepreneurial dimensions viz., Innovativeness, Risk Taking Propensity, Pro-Activeness, Competitive Aggressiveness and Autonomy were tested to assess their impact on the business performance. The entrepreneurial orientation and business performance relationship was found to be strong and significant indicating that the SMEs in Kurunegala district adopted better EO postures towards achieving promising returns in their business.
\end{abstract}

\section{Keywords}

Innovation, Risk Taking Propensity, Pro-Activeness, Competitive Aggressiveness, Autonomy, Entrepreneurial Orientation, Business Performance, Relationship

\section{Introduction}

Small industries have prominently been acknowledged as the major source of employment and livelihood across the rural areas of Sri Lanka. The respective governments in Sri Lanka since independence have invariably emphasized the importance and corresponding need for developing these small industries. The Cottage and Small Scale Industries have played a vital role in the economic development by generating employment opportunities, domestic savings mobiliza- 
tion, and poverty alleviation [1].

The development and expansion of SMEs in Sri Lanka by far has served multifarious merits. The SMEs have potential to generate significant socio-economic benefits with less capital investment and relatively limited infrastructure, proportionately absorbing more number of labour per unit of capital invested. Keeping in view that the agricultural sector alone cannot generate sufficient employment opportunities; the SMEs play a vital role in providing employment opportunities. The Department of Census and Statistics established that the investment per employee was nearly Rs. 9900 in small scale industries, Rs. 34,000 in medium industries and Rs. 66,700 in large scale industries [1]. The quality of employment provided by the large scale sector can be pronounced better compared to the small scale industries, in the rural areas. Nevertheless, the job opportunities provided in the rural areas have been helping to arrest the migration from rural to urban areas [2].

As the SMEs do not require huge investments, they have great potential to mobilize financial resources and a substantial amount of investment is financed by personal or domestic sources. SMEs serve as a catalyst to promote balanced regional development. They are integral elements of the overall poverty alleviation stratagem, channelized through the implementation of multiple development programs initiated by both government and non-government agencies. SMEs have developed as a platform for nurturing the entrepreneurial talent and training the workforce, albeit a larger section of employees recruited by SMEs in the rural areas lacks basic skills. SMEs also have another complementary role to play, through sub-contracting to the large industries, essentially facilitating the linkage.

The Government of Sri Lanka has provided a very conducive environment for starting small enterprises. The contribution of SMEs towards economic development is considerably low in Sri Lanka, although they have accounted for larger percentage of overall establishments. The medium sized establishments have contributed more to the employment generation and value addition as compared to the SMEs in Sri Lanka. In terms of the GDP of export sector in Sri Lan$\mathrm{ka}$, the small and medium enterprises contribute more than $70 \%$. Elaborating further, there are about 500 odd export related establishments generating business worth 11 billion dollars approximately. Out of these, 80\% represent the small and medium enterprises. Sri Lanka has extensive tea cultivation and it produces about 300 million kilograms of tea annually. Around $70 \%$ of the tea production in Sri Lanka comes from the small farmers whose land holding is less than an acre [3].

\section{Entrepreneurial Orientation}

Entrepreneurship is a major driving force for the country's economic growth as it creates employment opportunities, contributes in revenue generation, enhances the range of services and stimulates competitiveness. The SMEs play a 
significant role in this aspect and have been recognized as the major engine for the growth of economy in any country. Owing to the role played by the SMEs in generating employment and revenue, the factors that are affecting the growth of these SMEs have both political and economic relevance [4].

Entrepreneurial Orientation has been identified and emphasized as much imperative for the firms to grow and flourish in the dynamic and fast changing business environment, irrespective of their size [5]. Entrepreneurial Orientation has been acknowledged as the key determinant for the firm's success, profitability and sustained growth. Entrepreneurial Orientation comprises of innovation, risk taking in terms of endeavoring new products or services and acting proactively, to secure an edge over competitors. Because of the potential benefits it offers, the entrepreneurial orientation has become a subject of interest and relevant concern in the field of entrepreneurship and drawn the attention of researchers and practitioners [6]. The specific entrepreneurial orientation dimensions: innovativeness, autonomy, pro-activeness, risk taking propensity, competitive aggressiveness and autonomy are discussed in the subsequent sections.

\section{Measurement Variables}

The following dimensions of Entrepreneurial Orientation have been measured for assessing the relationship between EO and Business Performance:

\subsection{Innovativeness}

Innovativeness represents the tendency of any enterprise to support creativity, venturing into new products and services, novelty and experimentation which results into advanced technological processes, and innovative products \& services. It is an important means of exploring opportunities and hence identified as a significant component of entrepreneurship [7].

\subsection{Pro-Activeness}

It is the acumen to identify an opportunity and anticipate the demand to innovate, create and change the business environment and also the forward looking approach to combat the competition in introducing new products and services ahead of competitors. It is manifested in different ways such as aggressive attitude towards competitors and pursuit of opportunities favourable to the firm. It is the ability of the firm to take initiative as and when demand arises and the willingness to initiate, to which competitors respond [7].

\subsection{Risk Taking Ability}

Risk taking ability is represented as the spirited and courageous decision to venture into unexplored markets and allocating substantial amount of resources, uncertain of the outcomes. It is described by Wiklund \& Shepherd [8] as willingness to spare considerable resources which involve probability of high failures. Risk handling is a process where potential risks are identified, analyzed, 
intercepted and mitigated while balancing the costs of protecting the firm.

\subsection{Competitive Aggressiveness}

Competitive Aggressiveness refers to the firm's propensity to challenge the competitors directly and intensely to secure a robust entry into the market and strengthen its position, and outperform the competitors in the marketplace [9]. It is also referred as firm's willingness to be unconventional to capture the markets and respond to the competition sturdily. The literature affirms that time and again pro-activeness and competitive aggressiveness have been used interchangeably, albeit difference between these two dimensions persists.

\subsection{Autonomy}

Autonomy refers to the individual's or the team's actions in coming out with an idea or vision and carrying it for implementation [10]. It is the firm's ability to explore and identify opportunities on its own. Autonomy also refers to the actions taken freely, irrespective of the constraints in the organization, for the establishment and smooth functioning of the business venture. A strong relationship exists between autonomy and entrepreneurial orientation [10].

\subsection{Business Performance}

There is a lack of consensus among the researchers regarding the approach to measure the business performance indicators. As a result, range of performance measures such as objective and subjective, financial and non-financial have been taken into use, resulting in high diversity in the Entrepreneurial Orientation and Business Performance related studies [11]. Single dimension and narrow range of performance indicators when considered, may produce misleading results. Therefore, the question arises as to which are the best indicators for evaluating or measuring the performance, whether it should be financial indicators such as sales growth, profits, return on investment etc. or non-financial indicators such as satisfaction levels of the customers and stakeholders or both financial and non-financial parameters must be considered.

Researchers have argued that the objective measures of performance are more appropriate compared to the measures that are subjective in nature. Respondents are hesitant to share the important data of the firm; hence the objective measurement of performance serves as a challenge [12]. Firms would be willing to provide subjective evaluation of its business which in turn would be lacking the reliability. Lumpkin \& Dess [10] argued that business performance is uni-dimensional and hence it is useful to integrate measures of both objective and subjective nature, to evaluate the business performance.

\subsection{Entrepreneurial Orientation \& Business Performance}

The most widely studied topic in the field of entrepreneurship is the entrepreneurial orientation and the business performance relationship. There is a variation in the results from a strong positive relationship to an insignificant rela- 
tionship [13]. Owing to the inconsistency in the results of the previous studies, as adopting the entrepreneurial orientation requires resources [6], there emerges a need to carry out further studies to determine the valid circumstances under which an entrepreneurial orientation may be useful. Several studies have measured the entrepreneurial orientation as a uni-dimensional concept and accordingly haven't tested the relationship among the individual dimensions of the entrepreneurial orientation and the business performance. In Sri Lanka, it is observed that several entrepreneurs are investing their money and resources, yet unable to achieve the expected results. Hence it is important that the entrepreneurs should possess a clear understanding and knowledge about the entrepreneurial orientation and business performance relationship.

The topic of entrepreneurial orientation and the firm's business performance relationship over the years has received considerable attention and the researchers have theorized the incidence of entrepreneurial behaviors such as propensity to engage in risk taking, innovation and proactive behaviors being positively associated with the profit and growth of the organization [14]. Studies have revealed that firms that have adopted strong entrepreneurial orientation have performed better than the ones that haven't adopted the same [8].

Reviewing the literature on the entrepreneurial orientation and the business performance, the framework can be illustrated as shown in Figure 1.

The literature envisages that while the SMEs and their business performance is important to the Owner/CEO/Manager, but there is a lack of clear knowledge and information regarding which of the entrepreneurial factors influence the performance of SMEs and also how do they influence the performance.

Research Question: The research is aimed at examining the relationship between the entrepreneurial orientation and the business performance in the small and medium enterprises in Kurunegala District, Sri Lanka. The hypothesis formulated to address the research question as to what is the relationship between overall EO and business performance of SMEs in Kurunegala District?

\section{Literature Review}

For the success of an organization, entrepreneurial orientation is the key element.

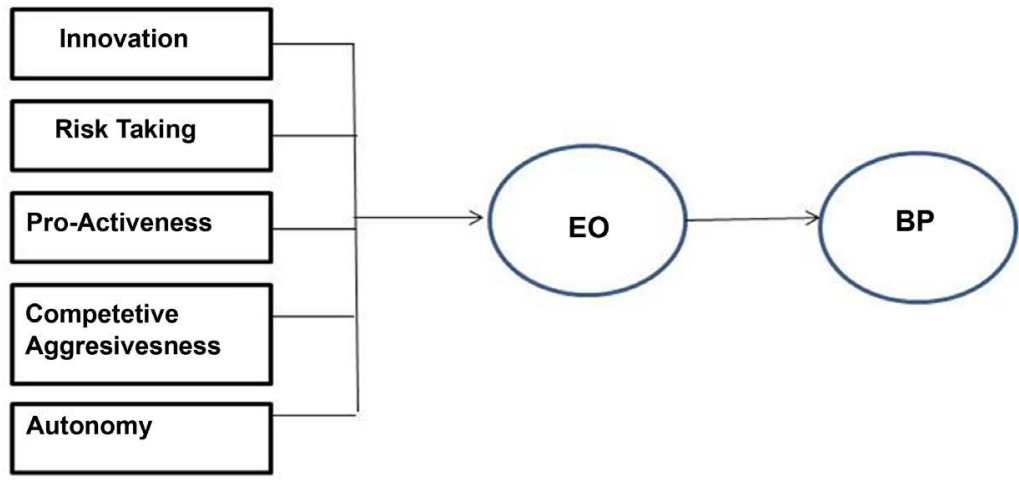

Figure 1. Framework. 
In the recent past, a larger emphasis has been on finding the relationship between entrepreneurship and business performance and relevant theories have been postulated to understand the incidence of entrepreneurial behaviour at firm level like risk taking ability, innovativeness, autonomy, competitive aggressiveness and pro-activeness which has positive relationship with the profitability or growth [10] [15].

Antoncic and Hisrich [16] stated that entrepreneurial orientation not only helps the firms employ unconventional thinking to address the problems but also it helps in gaining a brand identity for the firm. Firms can earn first mover advantage and pioneer in the market by continuous differentiation in the products and processes. Firms with high level of entrepreneurial orientation have opportunity to target premium segment of the market and command high prices ahead of their competitors [17]. Ireland [18] stated that creative leadership, astute resource management and participative culture are the antecedents of opportunity seeking behaviour, resulting into superior performance. Firms scan their environment continuously, identify potential opportunities, act promptly on the emerging opportunities and acquire added market share [19].

Tang et al., [20] reported that the relationship between entrepreneurial orientation and business performance is not straight, rather it is shaped like inverted $\mathrm{U}$, implies that either very high or very low entrepreneurial orientation is not desirable. It has been observed that the strength of the relationship between entrepreneurial orientation and the business performance vary with the type of performance measures taken into consideration. At times, the activities or processes adopted would lead to favourable performance on a selected dimension and at the same time un-favourable outcomes may be witnessed in terms of other performance dimensions [10]. Diversity of measures for assessing the performance such as objective or subjective, financial or non-financial have been widely used by researchers to operationalize the business performance [21]. This could be one of reasons for variations reported in the relationship between the entrepreneurial orientation and business performance.

Runyan \& Swinney [22] studied the relationship of entrepreneurial orientation (EO) and small business orientation (SBO), together the impact of these was assessed on small businesses in the United States. It was further assessed whether the effects are moderated by longevity of firms. They grouped the firms based on their age as relatively young or older firms. The results revealed that Entrepreneurial Orientation and Small Business Orientation are unique constructs per se and performance is different with respect to both of these. In case of younger firms, only the Entrepreneurial Orientation predicts the performance of the business; contrarily, in context of older firms, predominantly small business orientation predicts the performance. The literature reviewed indicated that largely the focus was on the entrepreneurial orientation and overall business performance, and individual dimensions of entrepreneurial orientation weren't considered that intricately.

Wiklund and Shephered [5] conducted a study on 413 Swedish firms applying 
the configurational approach to understand the relationship between the entrepreneurial orientation dimensions viz. innovativeness, pro-activeness and risk taking, for measuring the firm's performance. The financial capital and environment factors were considered as moderators of the entrepreneurial orientation and the results pointed out that entrepreneurial orientation positively influenced the business performance.

AzlinShafinaz Arshad et al., [23] conducted a survey on the SMEs in Malaysia to study the impact of entrepreneurial orientation on the business performance. Their observation indicated that all the four dimensions of entrepreneurial orientation namely innovation, risk taking, pro-activeness and competitive aggressiveness were the key predictors that affect the business performance of SMEs while autonomy was not found to be a significant dimension in business performance determination.

\section{Data Collection and Analysis}

A non-probabilistic approach of sampling was followed. In non-probabilistic sampling, it is assumed that the sample within the population has even characteristics and for that reason the results are more likely to be accurate. Therefore, we can pronounce that sample is a valid representative of the population. Especially with respect to social institution settings, non-probabilistic sampling is common as it saves time and resources. The data under study was collected through a questionnaire designed to meet the objectives and prerequisites of the present study, using a combination of judgment and conventional sampling.

A structured questionnaire was designed covering the demographics of the small and medium enterprises along with the entrepreneurial orientation dimensions and business performance. The questionnaire was split into three sections viz. first section incorporated the demographic details pertaining to the firm; the second part focusing on the business performance, followed by the third section including entrepreneurial orientation dimensions such as Innovation, Risk Taking Propensity, Pro-Activeness, Competitive Advantage, and Autonomy. The respondents were advised to respond on Likert's 5-point scale $(1=$ strongly disagree, $2=$ disagree; $3=$ neither agree nor disagree; $4=$ Agree and $5=$ Strongly Agree).

\section{Study Area}

Kurunegala District located in the North Western Province of Sri Lanka was chosen for the study. The district of Kurunegala is spread across an area of 4812.7 sqkms with an administrative segregation through Divisional Secretariats, GramaNiladari, Electorate Division, Municipal Councils, and Urban Councils. Kurunegala shares borders with five adjoining districts namely Anuradhapura in the North, Mathale in East, Gampaha and Kegalle towards South, and Puttalamon the Western side. The languages that are widely spoken in Kurunegala based on the prominent social classes and ethnic backgrounds are Sinhalese, 
Tamil and English. The most practiced religion in Kurunegala is Buddhism. It is also the home for Christianity, Hinduism and Islam. Kurunegala has a tropical rainforest climate which means it is hot throughout the year. The literacy rate was $92.7 \%$ as per the census of 2001 and the females dominate males in the literacy rate in Kurunegala district. Kurunegala has become the second most favoured location in the island for new investments.

A total of 275 small and medium enterprises in Kurunegala District in the North Western Province of Sri Lanka, have participated in the survey. Because of the limitations and restricted entry into the firms, data from only 275 firms could be collected which includes manufacturing and services at large. The details of their business activities are presented in Table 1.

The research was intended to examine the relationship between the Entrepreneurial Orientation and Business Performance. Hence, the respondents chosen were the owners or CEOs in some cases and at selected firms, in the absence of CEOs and owners; it was managers who were principally managing the firm. The scope of the study was restricted to the Small and Medium Enterprises in Kurunegala District. The study was undertaken at firm level.

Data was collected from 275 Small and Medium Enterprises located in the district of Kurunegala. The demographic profile of the data set is presented in Table 2.

$84 \%$ of SMEs were less than 10 years old and only $16 \%$ SMEs had been operating for more than 11 years. Further, 52\% of SMEs had less than 10 employees working with them and $50 \%$ of SMEs were small in terms of their annual turnover i.e. less than 50 million Sri Lankan Rupees (SLR). In total, 46\% respondents were from the manufacturing sector and 54\% represented the services sector.

Validity and reliability of the questionnaire used for the study were examined using Confirmatory Factor Analysis to test the relationships of constructs and the indicators. The reliability was examined using Cronbach's Alpha Coefficient (Table 3).

Table 1. Number of small and medium enterprises in Kurunegala participated in the survey.

\begin{tabular}{|c|c|c|c|}
\hline \# & Nature of the Firm & No. of firms visited & Nature of the Business Activity \\
\hline 1 & Agriculture & 6 & Coconuts, cut flowers, fruit and vegetables \\
\hline 2 & Construction \& Real Estate & 13 & Housing \&real estate \\
\hline 3 & Manufacturing & 126 & $\begin{array}{l}\text { Coconut milk, coir, animal feed, rubber } \\
\text { based products, apparels, toys, cement/clay } \\
\text { pots, detergents, jewelry, furniture and } \\
\text { packaging etc. }\end{array}$ \\
\hline 4 & Services & 116 & $\begin{array}{l}\text { Hotel, education, printing, food processing, } \\
\text { wedding planner etc. }\end{array}$ \\
\hline 5 & Trading & 14 & $\begin{array}{l}\text { Electrical items, garments, books and } \\
\text { stationery, vehicles, household-items, auto } \\
\text { spare parts, jewelry. }\end{array}$ \\
\hline
\end{tabular}


Table 2. Demographic profile of respondents.

\begin{tabular}{|c|c|c|c|}
\hline Factors & Details & Count & Percentage (\%) \\
\hline \multirow{5}{*}{ Age of the Firm } & Less than 5 years & 129 & 46.9 \\
\hline & 5 to 10 years & 101 & 36.7 \\
\hline & 11 to 15 years & 31 & 11.4 \\
\hline & More than 15 years & 14 & 5.0 \\
\hline & Total & 275 & 100.0 \\
\hline \multirow{5}{*}{$\begin{array}{l}\text { Size of the firm (by number of } \\
\text { employees working) }\end{array}$} & Less than 10 & 144 & 52.4 \\
\hline & 11 to 50 & 92 & 33.4 \\
\hline & 51 to 100 & 28 & 10.2 \\
\hline & More than 100 & 11 & 4.0 \\
\hline & Total & 275 & 100 \\
\hline \multirow{5}{*}{$\begin{array}{l}\text { Size of the firm (by yearly } \\
\text { turnover in SLR) }\end{array}$} & Less than 50 million & 137 & 49.8 \\
\hline & 51 to 100 million & 91 & 33.1 \\
\hline & 101 to 200 million & 30 & 10.9 \\
\hline & More than 200 million & 17 & 6.2 \\
\hline & Total & 275 & 100.0 \\
\hline \multirow{3}{*}{ Nature of the Firm } & Manufacturing & 126 & 45.8 \\
\hline & Services & 149 & 54.2 \\
\hline & Total & 275 & 100.0 \\
\hline
\end{tabular}

Table 3. Reliability of scale items.

\begin{tabular}{cc}
\hline Constructs & Cronbach's Alpha Coefficient \\
\hline Innovation & 0.81 \\
Risk Taking Propensity & 0.73 \\
Pro-Activeness & 0.70 \\
Competitive Aggressiveness & 0.80 \\
Autonomy & 0.69 \\
Business Performance & 0.72 \\
\hline
\end{tabular}

All the constructs viz., innovativeness, risk taking propensity, pro-activeness, competitive aggressiveness, autonomy and the indicators of business performance resulted in a value of more than 0.7 , hence it can be interpreted that the instruments were consistent and reliable.

\subsection{Descriptive Statistics of Entrepreneurial Orientation}

The mean and standard deviation of the entrepreneurial orientation dimensions and business performance variable are presented in Table 4.

The descriptive statistics indicate that pro-activeness and competitive aggressiveness have higher mean values than the average of all entrepreneurial orientation dimensions. Risk taking propensity and innovation are closer to the average of 
Table 4. Descriptive statistics for EO constructs-nature of the firm.

\begin{tabular}{ccc}
\hline Size of the Firm & Average & Std. Dev. \\
\hline Innovation & 3.550 & 0.952 \\
Risk Taking & 3.618 & 0.651 \\
Pro-Activeness & 3.972 & 0.684 \\
Competitive Aggressiveness & 3.675 & 0.780 \\
Autonomy & 3.442 & 0.589 \\
\hline
\end{tabular}

the EO dimensions. It indicates that SMEs are ready to seek opportunities and anticipate the demand to innovate, create and change the business environment. These SMEs are futuristic in their approach, primed to beat the competitors in introducing new products and services ahead of them and have the propensity to challenge the competitors directly or indirectly, well driven to enter the market and outperform the competitors. Also, it is identified that these SMEs that have been surveyed must improve on innovation and risk taking ability to defend and sustain their business, and upsurge their market share and overall business performance against their competitors. However, they face limitations when it comes to taking actions freely, owing to various organizational constraints.

\subsection{Entrepreneurial Orientation and Business Performance Relationship}

Confirmatory factor Analysis with Maximum Likelihood Model in the Structural Equation Modeling was used for analysis of data. Analysis was carried out on the summated measures of Entrepreneurial Orientation Dimensions (Innovation, Risk Taking, Proactiveness, Competitive Aggressiveness and Autonomy which are latentvariables) and Business Performance variables. The path diagram is presented in Figure 2.

The results shows that Normed Chi-Square of 2.854 (216.870/76 Degrees of Freedom), NFI $=0.916$; CFI $=0.943$; PNFI $=0.765$; PCFI $=0.788$ and $\mathrm{RMSEA}=$ 0.07 are all under the threshold limits indicating a good fit of the model. This indicates that the research model is accepted and meets the specified criteria.

The results in Table 5 indicates that all the constructs viz., innovativeness, risk taking propensity, pro-activeness, competitive aggressiveness, autonomy and the indicators of business performance resulted in a value of standardized loading factor $>0.5$, hence it can be interpreted that the instruments are valid in measuring the variables.

The results indicate that all the dimensions of entrepreneurial orientation have significant impact on the business performance $(\mathrm{P}<0.001)$. The hypothesis that entrepreneurial orientation dimensions have significant influence on the business performance is accepted.

\section{Conclusion}

Significant positive influence was found among all the dimensions of Entrepreneurial Orientation such as Innovativeness, Risk Taking Propensity, Pro-activeness, 


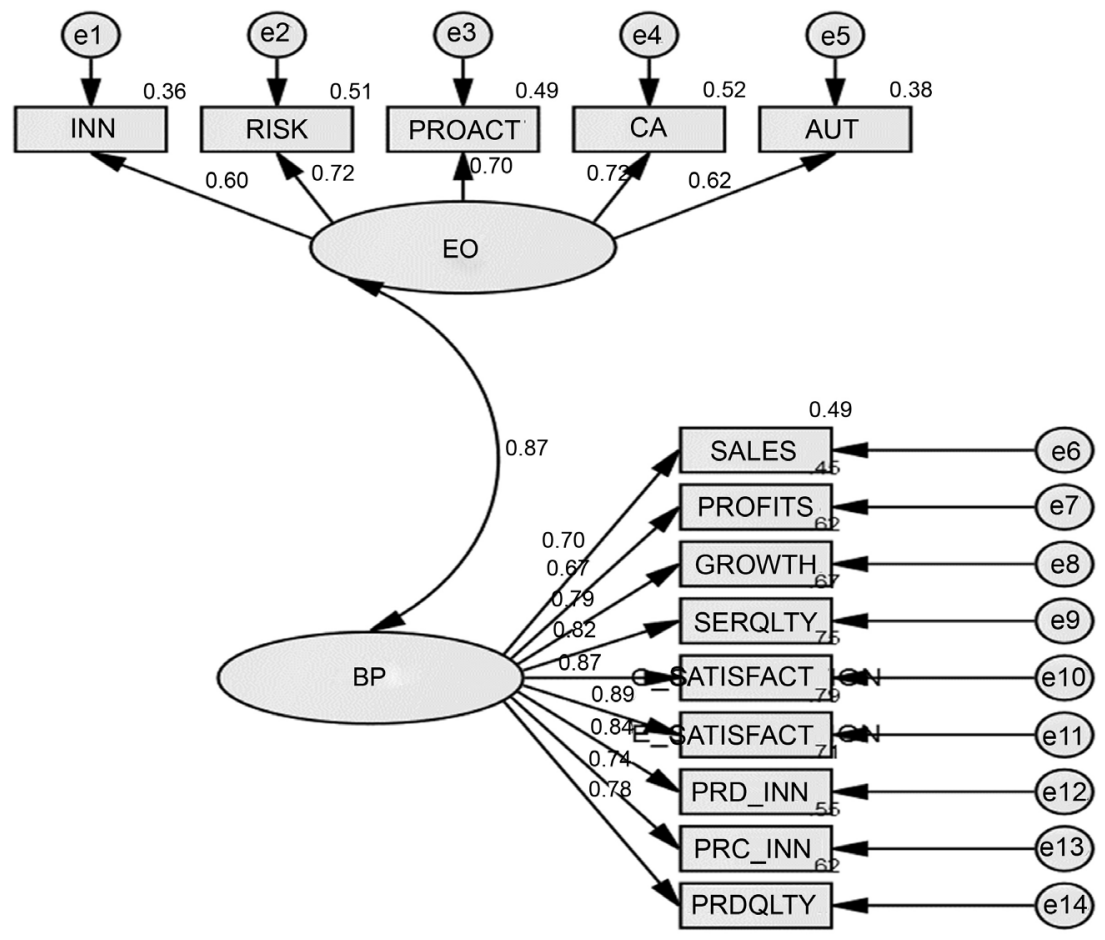

Figure 2. Path diagram of entrepreneurial orientation and business performance relationship.

Table 5. Standard regression coefficients.

\begin{tabular}{cccccccc}
\hline \multicolumn{2}{c}{ Dimension } & & $\begin{array}{c}\text { Standard Regression } \\
\text { Coefficients }\end{array}$ & Estimate & S.E. & C.R. & Prob \\
\hline Innovation & $\leftarrow$ & EO & 0.601 & 14.436 & 1.343 & 10.747 & $* * *$ \\
Risk Taking & $\leftarrow$ & EO & 0.737 & 4.790 & 0.497 & 9.628 & $* * *$ \\
Pro-activeness & $\leftarrow$ & EO & 0.700 & 5.920 & 0.590 & 10.040 & $* * *$ \\
Comp. Aggress. & $\leftarrow$ & EO & 0.714 & 10.712 & 1.083 & 9.892 & $* * *$ \\
Autonomy & $\leftarrow$ & EO & 0.622 & 5.816 & 0.548 & 10.616 & $* * *$ \\
Sales & $\leftarrow$ & BP & 0.699 & 0.651 & 0.059 & 11.119 & $* * *$ \\
Profits & $\leftarrow$ & BP & 0.667 & 0.647 & 0.058 & 11.212 & $* * *$ \\
Growth & $\leftarrow$ & BP & 0.790 & 0.604 & 0.057 & 10.678 & $* * *$ \\
Serqlty & $\leftarrow$ & BP & 0.817 & 0.633 & 0.061 & 10.461 & $* * *$ \\
Customer_Satis & $\leftarrow$ & BP & 0.867 & 0.383 & 0.039 & 9.834 & $* * *$ \\
Employee_Satis & $\leftarrow$ & BP & 0.889 & 0.344 & 0.037 & 9.374 & $* * *$ \\
Product_Innovation & $\leftarrow$ & BP & 0.844 & 0.594 & 0.058 & 10.177 & $* * *$ \\
Process Innovation & $\leftarrow$ & BP & 0.739 & 0.811 & 0.074 & 10.964 & $* * *$ \\
Product Quality & $\leftarrow$ & BP & 0.785 & 0.794 & 0.074 & 10.716 & $* * *$ \\
\hline
\end{tabular}

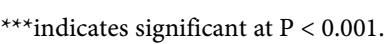

Competitive Aggressiveness, and Autonomy and the Business Performance. The entrepreneurial orientation and business performance relationship was found to 
be very strong and significant. It is an indication that the firms which took part in the survey in Kurunegala district are adopting better entrepreneurial orientation postures towards achieving higher returns in their businesses which is in confirmation of the research findings by [15] [24]. The small and medium enterprises in Kurunegala have shown significant influence of all the dimensions of entrepreneurial orientation on the business performance. However, these results cannot be generalized for all the SMEs in other provinces. These Small and Medium Enterprises have shown that the business performance can be achieved if the firms adopt better entrepreneurial dimensions such as innovativeness, risk taking propensity, pro-activeness, competitive aggressiveness and autonomy. It is important for the Small and Medium Enterprises to be more entrepreneurial in order to increase their market share and upsurge their business performance. The overall business scenario appears promising for these SMEs in Kurunegala district.

\section{Conflicts of Interest}

The authors declare no conflicts of interest regarding the publication of this paper.

\section{References}

[1] Antoncic, B. and Hisrich, R.D. (2004) Corporate Entrepreneurship Contingencies and Organizational Wealth Creation. Journal of Management Development, 23, 518-550. https://doi.org/10.1108/02621710410541114

[2] Gamage, A.S. (2003) Small and Medium Enterprise Development in Sri Lanka: A Review. Meijo Review, 22, 133-150.

[3] Arshad, A.S. Rasli, A., Arshad, A.A. and Zain, Z.M. (2014) The Impact of Entrepreneurial Orientation on Business Performance: A Study of Technology-Based SMEs in Malaysia. Procedia-Social and Behavioral Sciences, 130, 46-50. https://doi.org/10.1016/j.sbspro.2014.04.006

[4] Central Bank of Sri Lanka (1998) Economic Progress of Independent Sri Lanka, Central Bank of Sri Lanka, Colombo, 121-124.

[5] Covin, J.G. and Slevin, D.P. (1989) Strategic Management of Small Firms in Hostile and Benign Environments. Strategic Management Journal, 10, 75-87. https://doi.org/10.1002/smj.4250100107

[6] Covin, J.G. and Slevin, D.P. (1991) A Conceptual Model of Entrepreneurship as Firm Behavior. Entrepreneurship Theory and Practice, 16, 7-26. https://doi.org/10.1177/104225879101600102

[7] Covin, J.G., Green, K.M. and Slevin, D.P. (2006) Strategic Process Effects on the Entrepreneurial Orientation-Sales Growth Rate Relationships. Entrepreneurship Theory and Practice, 30, 57-81. https://doi.org/10.1111/j.1540-6520.2006.00110.x

[8] Dess, G.G. and Priem, R.L. (1995) Consensus-Performance Research: Theoretical and Empirical Extensions. Journal of Management Studies, 32, 401-417. https://doi.org/10.1111/j.1467-6486.1995.tb00782.x

[9] Ireland, R.D., Hitt, M.A. and Sirmon, D.G. (2003) A Model of Strategic Entrepreneurship: The Construct and Its Dimensions. Journal of Management, 29, 963-989. https://doi.org/10.1016/S0149-2063(03)00086-2 
[10] Jogaratnam, G. (2002) Entrepreneurial Orientation and Environmental Hostility: An Assessment of Small, Independent Restaurant Businesses. Journal of Hospitality and Tourism Research, 26, 258-277. https://doi.org/10.1177/1096348002026003004

[11] Krauss, S.I., Frese, M., Friedrich, C. and Unger, J.M. (2005) Entrepreneurial Orientation: A Psychological Model of Success among Southern African Small Business Owners. European Journal of Work and Organizational Psychology, 14, 315-344. https://doi.org/10.1080/13594320500170227

[12] Lee, S.M. and Lim, S. (2009) Entrepreneurial Orientation and the Performance of Service Business. Service Business, 3, 1-13. https://doi.org/10.1007/s11628-008-0051-5

[13] Lumpkin, G.T. and Dess, G.G. (1996) Clarifying the Entrepreneurial Orientation Construct and Linking It to Performance. Academy of Management Review, 21, 135-172. https://doi.org/10.5465/amr.1996.9602161568

[14] Lumpkin, G.T. and Dess, G.G. (2001) Linking Two Dimensions of Entrepreneurial Orientation to Firm Performance: The Moderating Role of Environment and Industry Life Cycle. Journal of Business Venturing, 16, 429-451. https://doi.org/10.1016/S0883-9026(00)00048-3

[15] Rauch, A., Wiklund, J., Lumpkin, G.T. and Frese, M. (2009) Entrepreneurial Orientation and Business Performance: An Assessment of Past Research and Suggestions for the Future. Entrepreneurship Theory and Practice, 33, 761-787. https://doi.org/10.1111/j.1540-6520.2009.00308.x

[16] Runyan, R., Droge, C. and Swinney, J. (2008) Entrepreneurial Orientation versus Small Business Orientation: What Are Their Relationships to Firm Performance? Journal of Small Business Management, 46, 567-588. https://doi.org/10.1111/j.1540-627X.2008.00257.x

[17] Athukorala, R. (2019) An SME Policy Finally in Sri Lanka. Daily FT E-Paper. http://www.ft.lk/rohantha-athukorala/A-SME-policy-finally-in-Sri-Lanka/19-641714

[18] Sapienza, H.J., Smith, K.G. and Gannon, M.J. (1988) Using Subjective Evaluations of Organizational Performance in Small Business Research. American Journal of Small Business, 12, 45-54. https://doi.org/10.1177/104225878801200304

[19] Tang, J., Tang, Z., Marino, L.D., Zhang, Y. and Li, Q. (2008) Exploring an Inverted U-Shape Relationship between Entrepreneurial Orientation and Performance in Chinese Ventures. Entrepreneurship Theory and Practice, 32, 219-239. https://doi.org/10.1111/j.1540-6520.2007.00223.x

[20] Valliere, D. (2006) Consequences of Growth: Shaping Entrepreneurial Attitudes. The International Journal of Entrepreneurship and Innovation, 7, 141-148. https://doi.org/10.5367/000000006778026626

[21] Venkatraman, N. and Ramanujam, V. (1986) Measurement of Business Performance in Strategy Research: A Comparison of Approaches. Academy of Management Review, 11, 801-814. https://doi.org/10.5465/amr.1986.4283976

[22] Wiklund, J. and Shepherd, D. (2003) Knowledge-Based Resources, Entrepreneurial Orientation, and the Performance of Small and Medium-Sized Businesses. Strategic Management Journal, 24, 1307-1314. https://doi.org/10.1002/smj.360

[23] Wiklund, J. and Shepherd, D. (2005) Entrepreneurial Orientation and Small Business Performance: A Configurational Approach. Journal of Business Venturing, 20, 71-91. https://doi.org/10.1016/j.jbusvent.2004.01.001

[24] Zahra, S.A. and Covin, J.G. (1995) Contextual Influences on the Corporate Entrepreneurship Performance Relationship: A Longitudinal Analysis. Journal of Business Venturing, 10, 43-58. https://doi.org/10.1016/0883-9026(94)00004-E 